\title{
Modern Trends of Ways to Protect Intellectual Property on the Internet
}

\author{
Elena Anatolyevna Kirillova ${ }^{1} \&$ Oleg Yevgenyevich Blinkov ${ }^{1}$ \\ ${ }^{1}$ Southwest State University, Kursk, Russian Federation \\ Correspondence: Elena Anatolyevna Kirillova, Southwest State University, 50 let Oktyabrya street 94, Kursk, \\ 305040, Russian Federation. E-mail: debryansk@mail.ru
}

Received: October 9, 2014 Accepted: November 30, 2014 Online Published: February 25, 2015

doi:10.5539/ass.v11n6p244 URL: http://dx.doi.org/10.5539/ass.v11n6p244

\begin{abstract}
Volume of copyright infringement on the Internet increases in arithmetic progression, so the search for legal tools that can provide a high level of protection of copyright on the Internet is a priority. In this paper the aim is to consider some issues of digitized works protection and develop main directions of copyright protection on the Internet. With development of digital technologies and expansion of the Internet, intellectual property has undergone a massive transformation. Copyright legal relationships in real information environment and digital information environment, as demonstrated by the comparative analysis, have significant differences. A huge number of works of science, literature, art, movies, soundtracks, images and computer programmes have become digitized by means of the Internet, which creates a possibility of the user access to unlimited information resources. The Internet is a one-world electronic information space with its attributes-cross-border information exchange, anonymity, self-development, unity and interactivity. This research led to the conclusion that the principle of quasi-free use of any information should be used by users on Internet for personal purposes, including copyright objects placed in the public domain on the Internet. Such model can be legally implemented by establishing a presumed consent by a copyright holder for the use of copyrighted material by users for personal use, if the author or copyright holder has not stated otherwise. A definition of "electronic work" and the concept of "public release" of a work were suggested based on the use of the Internet. The following conclusion is made in the article: a principle of free use of any information on the Internet should be used, including copyright objects placed in the public domain for private purposes, provided that an author or a right holder has not stated otherwise. Whereas the concept of "publication of a work", based on the use of intellectual property on the Internet, should be defined as a publication with the author's consent, regardless of a manufacturing method of copies, provided that such copies have been published in such quantity as to satisfy reasonable needs of users.
\end{abstract}

Keywords: digital environment, digitized works, counterfeiting, piracy, plagiarism

\section{Introduction}

Development of new digital technologies and the Internet has become an integral part of the modern society. Adapting copyright to the new realities of the digital environment is a serious problem. Copyright holders require ensuring effective protection of copyright in the digital environment, so that the community of users on the Internet does not threaten their authority (Ficsor, 2002).

One of the major trends of the information society is a rapid innovation development, which in the context of globalization leads to creation and use of new intellectual property which is in need of legal protection. In addition, active formation and development of a network information space, that have been observed in recent years, necessitated modifications and systematization of all regulations in force in the field of copyright in the global information space. As a result, in 1996, the World Intellectual Property Organization has adopted two new international agreements in the field of copyright: the WIPO Copyright Treaty, 20/12/1996 and WIPO Performances Phonograms Treaty, 20/12/1996.

It should be acknowledged that currently legislation governing the use of the Internet has already appeared in some countries, but a specific approach in applying it has not been elaborated yet.

With the advent of digital technologies new trends and issues in copyright have appeared which are defined by the following circumstances: 
- The concept of the material copy and copies of the work on the Internet lost its meaning;

- The concept of access to the product becomes more important than the concept of copying and duplicating on paper;

- Existing information space has become more highly integrated with the advent of cloud computing (WIPO, 2014);

- New problems occurred that relate to personal identification, a form of transactions, financial calculations, governance (Shyamkrishna, 2011);

- Before implementation of the principle of copyright protection allowed the honest publisher to fight the dishonest publisher, today with the development of the Internet the copyright holder has to fight with users (Lessig, 2007).

The World Intellectual Property Organization (WIPO) (Agreement Between..., 1996) highlights the most important issues for the possible creation of new tools of international copyright protection on the Internet, namely the protection of authors' rights, the rights of audiovisual performers and protection of sui generic databases that do not fall under copyright protection (Julie, 2007).

Rights of authors and audiovisual performers are already protected by the international treaties (RP and BF, 2008), but they need to be improved and updated. Additional activities in other areas are also in the stage of discussions that may give rise to a new form of international copyright protection in the digital environment (Portal WIPO, 2014).

One of the major trends of the information society formation is a "rapid innovation development, which in the context of globalization leads to creation and use of new intellectual property which is in need of legal protection" (David, 2013).

A main contradiction in this situation is that authors of works seek to profit from their work, and Internet users are willing to receive information free of charge. The core of this conflict is cheapening of copying technology and dissemination of information.

An opportunity provided to users in the digital era to copy and distribute information for free is a global challenge to copyright; therefore right holders are looking for ways to limit free exchange of information for users.

In addition, many researchers have repeatedly stressed that use of intellectual property on the Internet is a rapidly developing part of the economy, taxes, profits, so the problem of copyright directly affects interests of the state (Dorfman, 2010; Towse, 2013 et al.).

\section{Methods of Research}

In the study we used a general scientific dialectical method of cognition, involving objective and comprehensive knowledge of the studied phenomena and also used special methods of research such as: a systematic, comprehensive, comparative and legal analysis. We used private research methods, including methods of law interpretation, the studied structures were analyzed in relation to close legal categories. In the course of the study more than 20 sources on the topic were critically analyzed.

In the research, we used a general scientific dialectical method of cognition, which assumes an objectivity, and comprehensiveness of studying the phenomena under investigation, and special methods of investigation such as systemic, comprehensive, comparative and legal analysis as well.

Legislators in Western Europe and the United States, where civilized system of copyright protection is provided, today faced the need to adapt the current legal acts to further development of technical facilities taking into account the development of the Internet (Thomas, 2001).

Copyright infringement is the deliberate use of copyrighted intellectual property, without permission of the authors or copyright holders or violating conditions of a contract on the use of works, harming the individual and society (Dorrain, 2014). It is necessary to consider the most widespread copyright violation in the digital environment, namely the illegal use of copyright on the Internet.

Researchers state that counterfeit copies of works are subject to arrest in any country of the Berne Union (Dorfman, 2010), in which the work enjoys legal protection, while it is rightly noted that in the digital environment this concept of a counterfeit copy is difficult to apply (Jennifer, 2010). As a rule, a counterfeit copy is on a tangible medium-a server or a hard disk with legitimate information. Whether the arrest of counterfeit copies in such circumstances is an adequate measure, the answer is obvious; under such conditions the arrest of 
data storage as a counterfeit copy will be the measure violating the rights of third parties who have not committed illegal acts. In this regard it is necessary to consider the possibility of a broader approach to the notion of a counterfeit copy in the digital environment.

Researchers propose to divide the concept of "author's information product as an object of intellectual property created for commercial use" and "freely distributable author information product" (Dinusha, 2013). At the same time unless otherwise stated, the information product should be considered freeware. Keep in mind that the main differences between an electronic work from a printed work are in peculiarities of forms, in embodied requisites, as well as in document mediums. Some researchers have suggested the term "network publication"-information stored in the computer memory available for other users (Dane, 2002). However, this definition does not contain the original creative component of this activity, which characterizes any work.

According to paragraph 3 of Article 3 of the Berne Convention, published works mean works published with the consent of their authors, regardless of the method of manufacture of the copies, provided that such copies has been such as to satisfy the reasonable requirements of the public. The basis is still the concept of a copy (Statistic Berne Convention, 2014).

Many researchers have wondered: will placing the product on the Internet be considered as "publishing," given that any visitor of the website is often able to download any number of copies of electronic works with the same quality as the original (Shyamkrishna, 2012). Analysis of the provisions of the Agreed Statement concerning Article 6 and 7 of the WIPO Copyright Treaty gives reason for a negative answer to this question. Since the Agreed Statement states that the term "copy" refers only to hard copies of works that can be put into circulation as a material object (World Intellectual Property Organization, 2014). According to the World Intellectual Property Organization Copyright Treaty (1996) and the WIPO Performances and Phonograms Treaty (1996), the right to "public release" and bringing to public notice are treated not as the new author's authority, but as an extension of some of the old authorities previously recognized by the international practice (Kozhin, 2007). However, we should agree with the majority of researchers who define the right to "public release" in terms of development of the Internet as a new property authority (Lessig, 2007), using the argument that the World Intellectual Property Organization Copyright Treaty (1996) and the WIPO Performances and Phonograms Treaty (1996) concerned public display, public performance, broadcasting, across-the-wire communication. Unlike product placement on the public domain on the Internet, broadcasting is characterized in providing access to works to a limited number of persons, for a limited time in a limited area with no interactivity.

On this occasion, Cariou V. (2013) emphasizes that "dissemination of information products that are used worldwide, online affect territories of many countries. In his opinion, it rather implements the principle of extraterritoriality than the principle of territoriality". Many researchers rightly point out that there are questions about a possible transformation of the content of the principle of territoriality to its influence in present conditions, in connection with the use of intellectual property in the digital environment. The problem of jurisdiction in this regard is one of the key ones, the global nature of the new digital environment and anonymous access to the Internet makes it difficult to identify a location of copyright violators.

Gregory Klass (2008), in his turn, opposes the principle of extraterritoriality with the principle of flexible territoriality giving this argument: "in case of trans boundary copyright infringement a court will have to solve a problem of identifying a place of copyright infringement and in accordance with it apply the forum law or other laws".

We agree with this opinion, but it should be noted that the principle of extraterritoriality in international copyright protection, when establishing jurisdiction, shall be used in respect of products published on the Internet. According to many European researchers (Pamela Samuelson, Tara Wheatland, 2009 et al.) a return to the strict territoriality trial in cases of intellectual property infringement on the Internet is doubtful, since it ignores current realities as well as a practical necessity of implementing copyrights internationally.

\section{Results}

With regard to products published on the Internet, it is necessary to use the principle of extraterritoriality in the international protection of copyright when establishing jurisdiction, instead of the principle of territoriality, which is enshrined in international conventions, treaties and agreements.

1) In the global Internet the principle of quasi free use of any information should be used by users for personal purposes, including copyright objects placed in public domains on the Internet. Such model can be legally implemented by establishing a presumed consent of a copyright holder for use of copyrighted material by users for personal use, if the author or copyright holder has not stated otherwise. 
2) We should interpret an electronic product as the totality of ideas, thoughts, images that are results of creative activity, placed by users on the Internet, so that this information is available to other users of the network.

3) It's necessary to consider a broader approach to the concept of a counterfeit copy in the digital environment, as counterfeit copy is on a tangible medium-a server or a hard disk with legitimate information, in such conditions an arrest of storage data such as a counterfeit copy will be a measure violating the rights of third persons who have not committed illegal acts.

4) The term "public release of works" based on the use of intellectual property on the Internet, should be defined as publishing with the author's consent, regardless of the method of manufacture of the copies, if such copies has been such as to satisfy the reasonable needs of users. The fact of having access through the global information network to a product in the objective form on the computer usable storage medium is also considered as public release of a product. "This definition must be secured in international conventions, agreements, treaties in the field of copyright.

\section{Discussion}

Problems of improving the copyright law are of considerable interest to most countries in Western Europe and America. This is reflected by the systematic upgrading of the national legislation and the establishment of an international system for protection of authors and other copyright owners' interests.

With regard to the copyright protection in the digital environment, different and contradictory viewpoints were expressed. Bazedov Y. believes that "the evolution of copyright protection in the twenty-first century has not resulted in the thorough revision of the system of intellectual property rights" (Bazedov, 2014). The European movement for open sources software (the OPEN Software Sources) think that "copyright protection in the digital environment in any form is not necessary, and intellectual property protection on the Internet will have more negative than positive consequences in the light of the very specificity of development features of the digital environment" (Shalyto, 2003). U.S. lawmakers have an opposite point of view; in the U.S. a special law is adopted, which aims to protect authors' rights on the Internet-The Stop Online Piracy Act (SOPA, 2014). This law contains provisions that allow the right holder to block sites that host infringing works, to block domains, to initiate an arrest of funds of companies that own them. According to many European researchers (Geller, 2004), (Dinwoodie, 2009 and others) the fact that such legislation appeared leads to the conclusion that the legislation seeks to establish a strict system of legal regulation and control in the field of intellectual property rights on the Internet. Confirmation of these trends is the signing of Russian International trade agreement to combat counterfeiting (The Anti-Counterfeiting Trade Agreement-ACTA), which aims to counter violations of intellectual property rights in global networks (Pilieci, 2014). Experts pointed out that this document is very similar to the American bill SOPA (David, 2013) and legitimizes conducting searches on private territories to identify unlicensed products, to remove and destruct equipment used in manufacturing counterfeit products.

\section{Conclusion}

Copyright in all governments is based on the principle of a balance between personal interests of the author and the society's interests. The society is interested in gaining access to works, and the author, in turn, is interested in protecting his rights. The government's task is to allow both sides to realize their interests.

There are several approaches to address these issues. Proponents of the first approach believe that the key to the development of copyright is the maximum tightening of rules for turnover results of intellectual activity, reduction of free use of works. Another view is that unjustified increase of responsibilities for offenses in the sphere of intellectual property will only encourage the growth of a number of such offenses, will result in destabilizing of the society and in development of legal nihilism. The third approach is based on the desire to respect interests of all members of relations in the field of copyright in the digital environment, shaping legislation and law enforcement practice without an obvious shift in one direction or another.

In this research we concluded that excessive copyright protection could jeopardize democratic traditions and lead to violation of the principles of social justice through undue restrictions on access to information and knowledge. Too strict copyright protection restrains competition and innovation and inhibits creativity. Unfortunately the scope of the research didn't allow to consider a wider range of issues of intellectual property protection placed on the Internet, we can assume that further research will concern issues related to defining limits of legitimate use of copyright on the Internet; creating a legal tool to protect rights of copyright holders; monitoring implementation of copyright on the Internet in relation to information intermediaries; empowering copyright holders to control and administer rights to intellectual property on the Internet. 
Mechanisms of implementing copyright protection under modern conditions have started to become obsolete, have lost perspective and are no longer satisfactory neither for rights holders nor for consumers benefiting from intellectual property on the Internet. Therefore, further studies will follow the path of addressing issues relating to the copyright protection on the Internet, namely, studies aimed at the following factors must be conducted:

- To set limits of the legitimate use of copyright on the Internet;

- To elaborate legal instruments designed to protect copyright of right holders on the Internet;

- To propose methods for monitoring compliance with the copyright on the Internet with respect to information intermediaries and providers;

- To expand possibilities of authors and copyright holders to dispose and manage rights for intellectual property results on the Internet.

\section{References}

Agreement between the United Nations and the World Intellectual Property Organization. (1974). Retrieved July 6, 2014, from http://www.webcitation.org/65ny4z9Dx

Agreement between the World Intellectual Property Organization and the World Trade Organization. (1996, January 1). Retrieved July 4, 2014, from http://www.wipo.int/treaties/en/text.jsp?file_id=305582

Bazedov, Y. (n. d.). Foundations of Private International Law in Intellectual Proerty. Retrieved July 1, 2014, from http://www.toineika.jur.kyushu-u.ac.j/chizai/symposium

Cariou, V. (2013). Copyright-law-fair-second circuit holds that appropriation artwork need not comment on the original to be transformative. Prince, 714 F.3d. 694.

Dane, S. (2002). Ciolino \& Erin A. Donelon, Questioning Strict Liability in Copyright. RUTGERS L. REV., $54(351), 351$.

David, S. W. M. (2013). Right to integrity and the proposed resale royalty right and Notification right and the PRC copyright Law. Science and Technology, 40(2), 211-227.

Dinwoodie, G. B. (2009). Developing a Private International Intellectual Proerty Law: The Demise of Territoriality? William and Mary Law Review, 51, 715.

Dorfman, A. (2010). Can Tort Law Be Moral. RATIO JURIS, 23(205), 205-206. http://dx.doi.org/10.1111/j. 1467-9337.2010.00451.x

Dorrain, K. F. (2014). A Survey of Developments in Copyright Law: A Perspective from Cyberspace. Report Information from ProQuest. Retrieved July 6, 2014, from http://inkedin.com>pub/kristine-dorrain/ $5 / 717 / 810$

Ficsor, V. (2002). The law of Copyright and the Internet: The WIPO Treaties and Their Implementation (p. 750). Oxford University Press.

Geller, P. E. (2004). Conflict of Laws in Copyright Cases: Infringement and Ownership issues. Journal of the Copyright Society of the USA, 51, 337.

Jennifer, E. (2010). Rothman, Liberating Copyright: Thinking Beyond Free Speech. CORNELL L. REV., 95, 463.

Julie, E. (2007). Cohen, Creativity and Culture in Copyright Theory, 40 U.C. DAVIS L. REV., 1151, 178.

Kozhin, D. A. (2007). Right of bringing to public notice: Problems of theory and practice. Modern Law. Retrieved February 2, 2014, from http://www.juristlib.ru/book_3544.html

Lessig, L. (2007). Free Culture. How Big Media Uses Technology and the Law to Lock Down Culture and Control Creativity (pp. 62-64). The Pegnum Press.

Mendis, D. (2013). Digital Economy Act, 2010. Why the 'three strikes' law is not the answer to copyright law's latest challenge, International Review of Law. Computers \& Technology, 27(1-2), 60-84. http://dx.doi.org /10.1080/13600869.2013.764137

Pilieci, V. (2008). Copyright deal could toughen rules governing info on iPods, computers. Retrieved July 6 , 2014, fromhttp://www.canada.com/vancouversun/story.html?id=ae997868-220b-4dae-bf4f-47f6fc96ce5e\&p=1

Revised Program and Budget for the 2008/09 BIENNIUM. (2008). Approved by the Assemblies of the Member States of WIPO on 12.12.2008. 
Samuelson, P., \& Wheatland, T. (2009). Statutory Damages in Copyright Law: A Remedy in Need of Reform. 51 WM. \& MARY L. RE V, 439, 449.

Shalyto, A. A. (2003). A new initiative in programming. Foundation for Open Project documentation. $P C$ Week/RE, 40, 38 .

Shyamkrishna, B. (2011). The obligatory structure of copyright law. The Normativity of Private Law, O.J.L.S., $31,215$.

Shyamkrishna, B. (2012). The Normativity of copying in copyright law. Duke Law Journal (p. 221). Chang v. Virgin Mobile. Creative Commons.

SOPA-The Stop Online Piracy Act. Access mode. Retrieved July 1, 2014, from http://www.copyright. $\mathrm{ru} /$ ?file $=536$

Statistic Berne Convention for the Protection of Literary and Artistic Works. WIPO. Retrieved July 6, 2014, from http://www.webcitation.org/68kZsJdIx

Thomas, W. (2001). Merrill and Henry E. Smith. The Property Contact, 101. COLUM L. Rev., 773, 827-828.

Towse, R. (2013). The quest for evidence on the economic effects of copyright law. Cambridge Journal of Economics, 37, 1187-1202. http://dx.doi.org/10.1093/cje/bet014

WIPO Copyright Treaty, 20/12/1996 page 1/9 YH Collection of Laws for Electronic Access. Retrieved from http://en.wiki2.org/wiki/WIPO_Performances_and_Phonograms_Treaty

WIPO Performances Phonograms Treaty, 20/12/1996 page 2/13 YH Collection of Laws for Electronic Access.

WIPO portal for access to databases containing traditional knowledge. Retrieved July 7, 2014, from http://www.wipo.int/globalissues/databases/tkportal/index.html

\section{Copyrights}

Copyright for this article is retained by the author(s), with first publication rights granted to the journal.

This is an open-access article distributed under the terms and conditions of the Creative Commons Attribution license (http://creativecommons.org/licenses/by/3.0/). 